\section{(6) OPEN ACCESS}

\title{
Informing the 'early years' agenda in Scotland: understanding infant feeding patterns using linked datasets
}

\author{
Omotomilola Ajetunmobi, ${ }^{1}$ Bruce Whyte, ${ }^{2}$ James Chalmers, ${ }^{1}$ Michael Fleming, ${ }^{1}$ \\ Diane Stockton, ${ }^{1}$ Rachel Wood ${ }^{1}$
}

${ }^{1}$ Information Services Division, NHS National Services Scotland, Edinburgh, Scotland, UK

${ }^{2}$ Glasgow Centre for Population Health, Glasgow, Scotland, UK

\section{Correspondence to} Omotomilola Ajetunmobi, Area 151A, Information Services Division, NHS National Services Scotland, 1 South Gyle Crescent, South Gyle, Edinburgh, Scotland EH12 9EB, UK;

o.ajetunmobi@nhs.net

Received 8 April 2013 Revised 1 August 2013 Accepted 28 August 2013 Published Online First 15 October 2013

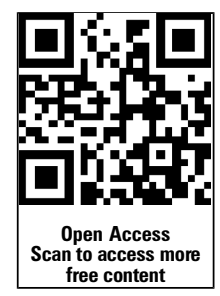

To cite: Ajetunmobi 0 , Whyte B, Chalmers J, et al. $J$ Epidemiol Community Health 2014;68:83-92.

\section{ABSTRACT}

Background Providing infants with the 'best possible start in life' is a priority for the Scottish Government. This is reflected in policy and health promotion strategies to increase breast feeding, which gives the best source of nutrients for healthy infant growth and development. However, the rate of breast feeding in Scotland remains one of the lowest in Europe. Information is needed to provide a better understanding of infant feeding and its impact on child health. This paper describes the development of a unique population-wide resource created to explore infant feeding and child health in Scotland.

Methods Descriptive and multivariate analyses of linked routine/administrative maternal and infant health records for 731595 infants born in Scotland between 1997 and 2009.

Results A linked dataset was created containing a wide range of background, parental, maternal, birth and health service characteristics for a representative sample of infants born in Scotland over the study period. There was high coverage and completeness of infant feeding and other demographic, maternal and infant records. The results confirmed the importance of an enabling environmentcultural, family, health service and other maternal and infant health-related factors - in increasing the likelihood to breast feed.

Conclusions Using the linked dataset, it was possible to investigate the determinants of breast feeding for a representative sample of Scottish infants born between 1997 and 2009. The linked dataset is an important resource that has potential uses in research, policy design and targeting intervention programmes.

\section{INTRODUCTION}

The importance of linked administrative datasets in epidemiological research is gaining increasing prominence. ${ }^{12}$ Linked datasets are a cost effective resource for designing population-wide interventions, monitoring population health, evaluating health outcomes and identifying best clinical practice. Such data provide intelligence that could influence a wide range of policy issues including infant nutrition.

Infant feeding policies that are informed by relevant contextual data spanning demographic, psychosocial, healthcare, community and public policy attributes can potentially provide a foundation for developing effective intervention programmes. ${ }^{3} 4$ This is particularly pertinent to the Scottish Government's early years agenda, which aims to provide 'every child with the best possible start in life' by delivering integrated services for early intervention that secure positive health outcomes and address health inequalities. ${ }^{5} 6$

Breastfeeding rates in Scotland remain among the lowest in Europe and have been relatively unchanged since $1990 .^{7-9}$ About half of the infants born annually are exclusively breast fed at birth and a quarter continue to breast feed exclusively up to their 6-8-week review. ${ }^{10}$

Different sources of breastfeeding data in Scotland currently provide some of the picture for the whole population, for example, the Guthrie test data ${ }^{91}$ and the Child Health Systems Programme-Pre SchoolCHSP-PS, ${ }^{10}$ or all of the picture for some of the population, for example, the Millennium Cohort Study, ${ }^{12}$ the 5 yearly Infant Feeding Survey ${ }^{13}$ and the Growing Up in Scotland-GUS study. ${ }^{14}$

Although there is extensive evidence of the protective effects of breast feeding, ${ }^{15}{ }^{16}$ there remains a paucity of information on the patterns of breast feeding in Scotland, ${ }^{3} 1217$ in particular how family background and health service-related factors influence the likelihood to breast feed.

This paper summarises a linkage study set up to investigate factors that influence the likelihood and patterns of infant feeding in Scotland using population-level administrative data.

\section{METHOD}

Development of the linked dataset Method/design

The creation of the linked dataset was proposed as part of a research project jointly funded by the Scottish Collaboration for Public Health Research and Policy and the Glasgow Centre for Population Health (GCPH). The project linkage was set up under the guidance of GCPH and a project advisory group. Information Services Division (ISD) Scotland created the linked dataset, which comprised anonymised extracts of birth records linked to maternal, infant and child health records (see box 1) for all infants born in Scotland over a 13-year period, 1997-2009. Approval for the project design and confidentiality of patient data was obtained from the Privacy Advisory Committee of NHS National Services Scotland-a body set up to ensure appropriate use of patient identifiable information. ${ }^{18}$ Further ethical approval was not required.

\section{Linkage process}

All births registered in Scotland between 1997 and 2009 were linked to the CHSP-PS records using probability matching techniques applied to personal identifiers within each dataset such as surname 
Box 1 Components of the linked dataset

- National Records of Scotland Birth Records: comprising all births in Scotland, which are registered by law within 21 days. The registration includes information on the country of birth of the mother and father, occupation, socioeconomic status, marital status, maternal parity, an indicator of multiple births, infant sex, live or stillbirth.

- The Maternity and Neonatal Linked Database: a permanently linked scheme developed by ISD, containing maternal obstetric discharge records (SMR02), neonatal discharge records (SMR11), Scottish birth records (SBR-replaced SMR11 in 2003), and vital events of births and deaths held by the National Records of Scotland (formerly the General Register Office for Scotland) since 1975.

- The Child Health Systems Programme Pre-School data: introduced in 1991 and collates information on child health from birth until shortly after school entry. Information on breast feeding is collected in two parts of the core programme (at the first visit—after discharge following child birth and 6-8-week review) via a recall interview with the mother/primary carer by a health visitor or public health nurse. The information collected includes parental background (eg, maternal age, father/partner's age), measures of growth/development and health behaviour (height, weight, maternal smoking status, exposure to passive smoking, type of infant feeding at birth, hospital discharge, first visit and the 6-8 week review) (details on ISD websitehttp://www.isdscotland.org/Health-Topics/Child-Health/ChildHealth-Programme/Child-Health-Systems-ProgrammePre-School.asp).

(transformed to Soundex code), first initial, date of birth, sex and postcode of residence. ${ }^{19}$ Using this approach, pairs of records are compared and a 'score' or 'weight' given to the paired identifiers reflecting the likelihood of a true match. Weights from individual identifier comparisons were added to provide a cumulative weighted score and a threshold set to accept or reject linkage pairs based on the weighted scores. ${ }^{20}$

There were two main stages to the linkage process. A probability matching process allowed the Community Health Index (CHI) number - a unique patient identifier used on Scottish health records- to be allocated to birth registration records held within ISD's Maternity and Neonatal Linked Database (MNLD). Following this, each child health record was probability matched against records within the MNLD. The addition of the $\mathrm{CHI}$ number from the first linkage improved the matching process. The linked dataset released for analysis was anonymised and contained one record per child with variables coming from several different sources, namely, the birth and death registration records, maternal and child health records (figure 1). Markers for infants who migrated (based on CHI database) were also included in the dataset.

\section{Additional derived information}

Geographical information, including output area, data zone, council area, intermediate zone and area characteristics based on the Scottish Index for Multiple Deprivation (SIMD-2006 version), were derived from the postcode on the birth registration address and added to the dataset. The dataset also included a marker for siblings of the same mother.

In addition, the ethnic and religious backgrounds of the parents were derived from the mother's forename and maiden name and the father's forename and surname using Onomap software. Onomap is a package designed by the University of London to classify names into groups of cultural, ethnic and linguistic origin ${ }^{21}$ and has been validated in Scotland. ${ }^{22}$ This was included to provide additional information on 'latent' cultural factors that may influence infant feeding patterns. For example, cultural affiliations of second or third generation immigrants could be derived using the mother's country of origin.

\section{Analysis}

Using the linked dataset, descriptive and multivariate (logistic regression) analyses were conducted to show demographic trends, describe patterns of infant feeding and explore the independent associations between a wide range of predictive variables (ie, parental, maternal, infant health and delivery characteristics) and infant feeding outcomes (SPSS V.17). Infant deaths, non-Scottish residents and invalid review records were excluded from the analysis.

\section{RESULTS}

\section{Description of the linked dataset}

The dataset consisted of 731595 records of infants born between 1997 and 2009, 613900 of whom had corresponding child health surveillance (CHSP-PS) records, $84 \%$ of the birth cohort. The coverage of CHSP-PS increased progressively over the study period with the phased roll out of the system within Scotland. Child records that linked to more than one infant in the cohort (ie, 'bad links') were minimal and were estimated to make up less than $1 \%$ of the population $(0.3 \%)$. A total of 722180 of the births were registered in Scotland; an additional $9415(1 \%)$ had child health surveillance records but no information collected by the national birth registry. The latter may refer to infants born outside Scotland (hence not recorded in vital events) or errors in the linkage and/or recording systems; in the analyses, these records were excluded.

The linked dataset contained a wide range of variables associated with infant feeding. Birth registration records provided the most comprehensive recording and coverage of demographic variables and details not available in other recording schemes, for example, information on mother's (and father's) country of birth, socioeconomic status and marital status. The child health surveillance scheme was the main source of breastfeeding information with over $90 \%$ of the records having complete and valid infant feeding fields. Data were collected for infant feeding at 10 days after birth and the 6-8 week review; feeding was defined as the 'predominant mode of infant feeding in the previous $24 \mathrm{~h}$ ', that is, exclusive breast feeding, bottle (or formula) feeding and mixed 'breast and bottle/formula' feeding. From 2001, data were also collated on feeding at birth and hospital discharge. Unlike the birth registration and CHSP-PS schemes, completeness of the Scottish Morbidity records was dependent on the type of data field, that is, mandatory or optional. Variables such as the 'mode of delivery', a mandatory field, had a higher rate of completion than 'ethnicity', an optional field, which was poorly recorded.

\section{Description of cohort, maternal characteristics and birth delivery details}

Overall, the 1997-2009 cohort was made up of 3\% multiple births, $51 \%$ male and $48 \%$ female. About a third of the infants 

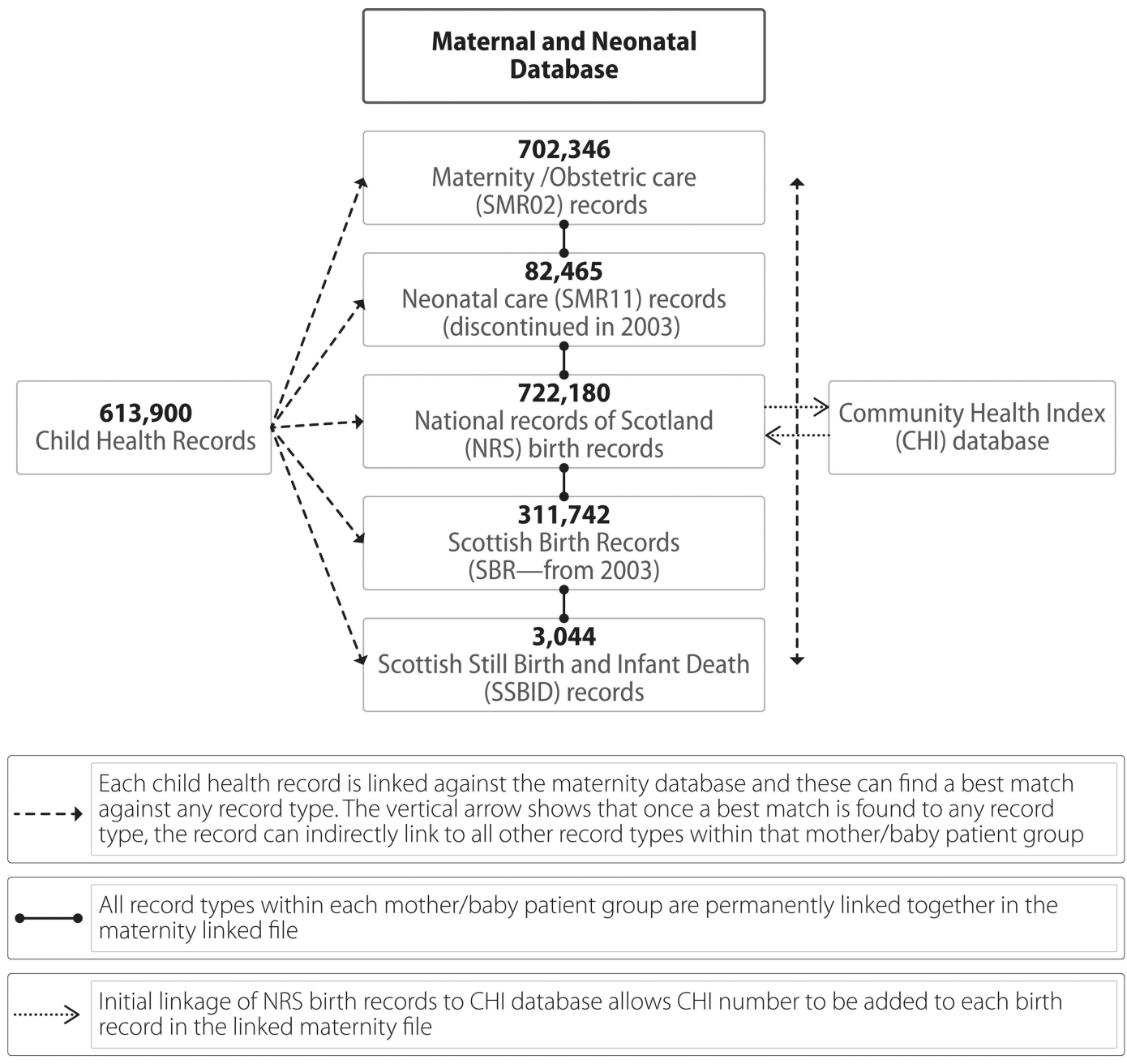

CHI: community health index; NRS: National Records of Scotland, formerly GROS; SMRO2: Scottish morbidity records for maternity/obstetric care; SMR11: Scottish morbidity records for neonatal care; SBR: Scottish birth records; SSBID: Scottish stillbirth and infant death record.

Figure 1 Description of the linkage process.

(31\%) were sibling pairs (infants of the same mother within the same cohort). Over the study period, births to mothers born outside the British Isles increased from 5\% in 1997 to $13 \%$ in 2009. Similarly, there was an increase in births to older mothers; the proportion of first time mothers aged 35 years or older doubled over the study period from $7 \%$ in 1997 to $14 \%$ in 2009. Overall, $60 \%$ of the infants were born via normal/ spontaneous delivery, $98 \%$ of which took place within a hospital setting. There was an increasing trend in caesarean sections from $18 \%$ in 1997 to $26 \%$ in 2009 . More than a half $(55 \%)$ of the births took place in a fully accredited baby friendly institution (table 1). Overall, $4 \%$ of the cohort had migrated by the age of 2 years.

\section{Description of the derived characteristics (OnoMAP, SIMD)}

In the 1997-2009 birth cohort, a quarter of the infants were resident in the $20 \%$ most deprived areas of Scotland (quintile) and $18 \%$ in the $20 \%$ least deprived areas at the time of birth (derived from the postcode recorded at birth registration). Most of the infants had parents of British ethnic origin (84\%), mothers of a British birth and origin (89\%) and mothers of a Christian religious background (95\%). The trends however were toward increasing ethnic and religious diversity. For example, there was an increase in mothers of a non-British birth and
non-British origin, that is, 'first generation immigrants' from 2\% in 1997 to $9 \%$ in 2009 (table 1).

\section{Description of characteristics associated with infant feeding}

Breastfeeding rates over the period 2001-2009 showed that about a half of infants were exclusively breast fed at birth, but this decreased steadily with increasing time from birth, to $44 \%$ by hospital discharge, to $37 \%$ by the first visit ( 10 days after birth) and to $25 \%$ by the $6-8$-week review. Exclusive breastfeeding trends have been relatively unchanged over the study period while, in contrast, mixed 'bottle and breastfeeding' trends increased steadily over the same period (figure 2).

There were however varying patterns across the population. Table 1 shows the characteristics of the population overall and changes in the characteristics of the population over the survey period. It also outlines changes in crude (unadjusted) rates for exclusive and mixed feeding at the first review. Greater rates of exclusive breast feeding (and mixed feeding) were observed among infants of older mothers, of mothers of non-British birth, of mothers of a higher socioeconomic status, of married parents, of non-smoking mothers, of multiparous mothers and those resident in less deprived areas. The rising trend in mixed feeding was observed among all categories of infants. Further multivariate analyses were based on 'any' breast feeding because of the similar profile between mixed and exclusively breastfed infants. 
Table 1 Descriptive characteristics and unadjusted infant feeding trends in the birth cohort

\begin{tabular}{|c|c|c|c|c|c|c|c|c|}
\hline \multirow[b]{2}{*}{ Background, maternal and infant health characteristics } & \multicolumn{2}{|c|}{ Full cohort } & \multicolumn{2}{|c|}{$\begin{array}{l}\text { Characteristic as \% } \\
\text { of cohort }\end{array}$} & \multicolumn{2}{|c|}{$\begin{array}{l}\text { Exclusive breast } \\
\text { feeding (at first } \\
\text { review) }\end{array}$} & \multicolumn{2}{|c|}{$\begin{array}{l}\text { Mixed breast feeding } \\
\text { (at first review) }\end{array}$} \\
\hline & n & $(1997-2009)(\%)$ & $1997(\%)$ & $2009(\%)$ & $1997(\%)$ & $2009(\%)$ & $1997(\%)$ & $2009(\%)$ \\
\hline \multicolumn{9}{|l|}{ Mother's age } \\
\hline$<20$ years & 56921 & 8 & 8 & 7 & 6 & 6 & 3 & 3 \\
\hline $20-24$ years & 130522 & 18 & 18 & 19 & 12 & 12 & 6 & 6 \\
\hline $25-29$ years & 193247 & 27 & 32 & 27 & 23 & 25 & 9 & 9 \\
\hline $30-34$ years & 210922 & 29 & 29 & 27 & 33 & 35 & 11 & 12 \\
\hline $35-39$ years & 109044 & 15 & 11 & 16 & 37 & 37 & 11 & 13 \\
\hline $40+$ & 19795 & 3 & 2 & 4 & 43 & 37 & 11 & 16 \\
\hline \multicolumn{9}{|l|}{ Mother's country of birth } \\
\hline Africa & 9103 & 1.3 & 1 & 2 & 73 & 64 & 11 & 22 \\
\hline Asia & 20152 & 2.8 & 2 & 4 & 48 & 50 & 18 & 30 \\
\hline Australasia & 2932 & 0.4 & 0.4 & 0.4 & 68 & 71 & 6 & 11 \\
\hline British Isles & 662568 & 91.6 & 94 & 86 & 36 & 33 & 3 & 8 \\
\hline Europe & 21724 & 3.0 & 2 & 6 & 59 & 66 & 5 & 14 \\
\hline North America & 4605 & 0.6 & 1 & 1 & 64 & 68 & 7 & 16 \\
\hline South America & 1068 & 0.1 & 0.1 & 0.2 & 92 & 64 & 5 & 27 \\
\hline Not known & 1488 & 0.2 & 0.2 & 0.4 & 100 & - & 0 & - \\
\hline \multicolumn{9}{|l|}{ Mother's smoking status at first visit } \\
\hline Managerial/professional & 195716 & 27 & 23 & 29 & 63 & 55 & 4 & 10 \\
\hline Intermediate & 162841 & 23 & 22 & 21 & 40 & 34 & 4 & 7 \\
\hline Routine/semiroutine occupation & 207308 & 29 & 32 & 26 & 23 & 26 & 3 & 6 \\
\hline Other/economically inactive & 157775 & 22 & 22 & 24 & 27 & 28 & 4 & 8 \\
\hline \multicolumn{9}{|l|}{ Marital status-parents } \\
\hline Married & 397227 & 55 & 62 & 50 & 46 & 50 & 4 & 12 \\
\hline Cohabiting & 208625 & 29 & 21 & 35 & 28 & 28 & 3 & 7 \\
\hline Joint registration—different addresses & 71709 & 10 & 9 & 11 & 17 & 15 & 2 & 5 \\
\hline Single parent & 44619 & 6 & 7 & 4 & 16 & 15 & 2 & 7 \\
\hline \multicolumn{9}{|l|}{ Mother's smoking status at first visit } \\
\hline Non-smoker & 422444 & 58 & 47 & 69 & 46 & 42 & 4 & 10 \\
\hline Smoker & 135860 & 19 & 20 & 16 & 18 & 14 & 3 & 5 \\
\hline Other/unknown & 165336 & 23 & 33 & 15 & 39 & 35 & 4 & 9 \\
\hline \multicolumn{9}{|l|}{ Mode of delivery } \\
\hline Normal/spontaneous & 448131 & 62 & 69 & 55 & 37 & 38 & 3 & 8 \\
\hline Instrumental & 85820 & 12 & 11 & 12 & 41 & 39 & 4 & 10 \\
\hline Breech & 3431 & 0 & 0.6 & 0.4 & 31 & 30 & 5 & 16 \\
\hline Caesarean-elective & 62996 & 9 & 7 & 10 & 34 & 33 & 5 & 11 \\
\hline Caesarean-emergency & 101294 & 14 & 11 & 14 & 36 & 33 & 5 & 12 \\
\hline Other unknown & 21968 & 3 & 2 & 9 & 20 & 0 & 0 & 20 \\
\hline \multicolumn{9}{|l|}{ Parity } \\
\hline First time mother & 321815 & 44 & 43 & 46 & 36 & 36 & 4 & 8 \\
\hline Multiparous mother & 401825 & 56 & 57 & 54 & 39 & 37 & 4 & 10 \\
\hline \multicolumn{9}{|l|}{ Neonatal admission } \\
\hline Not admitted & 607293 & 84 & 66 & 83 & 38 & 37 & 3 & 9 \\
\hline Admitted for up to 2 days & 26110 & 4 & 3 & 3 & 29 & 28 & 4 & 9 \\
\hline Admitted for more than 2 days & 44346 & 6 & 5 & 5 & 30 & 28 & 7 & 12 \\
\hline Other/unknown & 45891 & 6 & 25 & 9 & 37 & 38 & 4 & 9 \\
\hline \multicolumn{9}{|l|}{ Postnatal stay in hospital } \\
\hline 2 days or shorter & 319623 & 44 & 34 & 52 & 34 & 36 & 3 & 8 \\
\hline 3 days or longer & 381420 & 53 & 65 & 39 & 40 & 37 & 4 & 13 \\
\hline \multirow[t]{2}{*}{ Other unknown } & 22597 & 3 & 1 & 9 & 42 & 33 & 7 & 16 \\
\hline & & & & & 39 & 38 & 6 & 9 \\
\hline \multicolumn{9}{|l|}{ Derived variables } \\
\hline Mother's background-Onomap & & & & & & & & \\
\hline British birth and British origin & 641174 & 89 & 92 & 82 & 36 & 33 & 3 & 7 \\
\hline British birth and non-British origin & 18093 & 3 & 2 & 3 & 43 & 36 & 7 & 13 \\
\hline Non-British birth and British origin & 23708 & 3 & 3 & 4 & 58 & 61 & 6 & 13 \\
\hline
\end{tabular}


Table 1 Continued

\begin{tabular}{|c|c|c|c|c|c|c|c|c|}
\hline \multirow[b]{2}{*}{ Background, maternal and infant health characteristics } & \multicolumn{2}{|c|}{ Full cohort } & \multicolumn{2}{|c|}{$\begin{array}{l}\text { Characteristic as \% } \\
\text { of cohort }\end{array}$} & \multicolumn{2}{|c|}{$\begin{array}{l}\text { Exclusive breast } \\
\text { feeding (at first } \\
\text { review) }\end{array}$} & \multicolumn{2}{|c|}{$\begin{array}{l}\text { Mixed breast feeding } \\
\text { (at first review) }\end{array}$} \\
\hline & n & $(1997-2009)(\%)$ & $1997(\%)$ & $2009(\%)$ & $1997(\%)$ & $2009(\%)$ & $1997(\%)$ & $2009(\%)$ \\
\hline Non-British birth and non-British origin & 31772 & 4 & 2 & 9 & 57 & 62 & 16 & 23 \\
\hline Mother of unknown birth/origin & 8893 & 1 & 1 & 2 & 45 & 46 & 10 & 18 \\
\hline \multicolumn{9}{|l|}{ Parental background—Onomap } \\
\hline Both parents of British origin & 604964 & 84 & 86 & 78 & 38 & 35 & 3 & 8 \\
\hline Mother of British origin and father of non-British origin & 17579 & 2 & 2 & 4 & 53 & 51 & 5 & 12 \\
\hline Mother of non-British origin and father of British origin & 15555 & 2 & 2 & 3 & 55 & 50 & 5 & 13 \\
\hline Both parent of non-British origin & 29674 & 4 & 3 & 7 & 49 & 58 & 16 & 24 \\
\hline One parent of unknown origin & 55868 & 8 & 8 & 8 & 18 & 23 & 2 & 10 \\
\hline \multicolumn{9}{|l|}{ Maternal religious background—Onomap } \\
\hline Christian & 687489 & 95 & 96.7 & 92.7 & 37 & 36 & 3 & 8 \\
\hline Muslim & 18758 & 3 & 1.8 & 3.3 & 48 & 49 & 18 & 28 \\
\hline Buddhist & 4319 & 1 & 0.4 & 1.0 & 42 & 45 & 12 & 26 \\
\hline Sikh & 1757 & 0 & 0.2 & 0.3 & 55 & 59 & 15 & 26 \\
\hline Hindu & 1924 & 0 & 0.1 & 0.5 & 47 & 47 & 4 & 20 \\
\hline Jewish & 448 & 0 & 0.1 & 0.1 & 44 & 48 & 6 & 14 \\
\hline Not applicable & 8945 & 1 & 0.7 & 2.1 & 45 & 46 & 10 & 18 \\
\hline \multicolumn{9}{|l|}{ Area deprivation—SIMD 2006} \\
\hline SIMD 1: Most deprived & 181612 & 25 & 26 & 25 & 19 & 23 & 3 & 8 \\
\hline SIMD 2 & 145486 & 20 & 20 & 21 & 31 & 30 & 3 & 8 \\
\hline SIMD 3 & 134500 & 19 & 19 & 19 & 41 & 39 & 4 & 9 \\
\hline SIMD 4 & 130752 & 18 & 17 & 18 & 50 & 48 & 5 & 10 \\
\hline SIMD 5: Least deprived & 129719 & 18 & 18 & 17 & 61 & 54 & 5 & 12 \\
\hline
\end{tabular}

Univariate descriptive analysis highlighted clear associations among a range of parental, maternal health/delivery, infant and hospital characteristics and infant feeding. For example, higher breastfeeding rates were noted among infants of first generation immigrants (mothers of non-British birth and non-British ethnic origin) compared with 'second generation' immigrants (mothers of British birth and non-British origin). Mothers of British birth and origin, representing $89 \%$ of the cohort, consistently had the lowest level of breast feeding at each review (figure 3 ).

Multivariate analysis identified a range of parental and hospital-related factors that independently increased the relative likelihood to establish and continue any breast feeding (at the first visit and 6-8-week review). These included having an older mother, one or both parents being of non-British birth or origin, having married parents, being a female infant, infants with longer postnatal stay in hospital, being born in a baby friendly unit, infants born post-term, infants of first-time mothers and those resident in non-urban settings or one of the less deprived areas. In contrast, there was relatively less likelihood of breast feeding among infants of multiple births, infants of single or cohabiting parents, of mothers who smoked, of mothers or fathers of a lower socioeconomic status, among preterm infants, those admitted to a neonatal unit and infants born via instrumental and caesarean section (table 2).

\section{DISCUSSION}

Our findings emphasise the important influence of cultural, familial, socioeconomic and health service factors on infant feeding patterns and trends in Scotland. The creation of a child and maternal dataset was based on the linkage of a wide range
Figure 2 Trends in mixed 'bottle and breast feeding' 2001-2009.

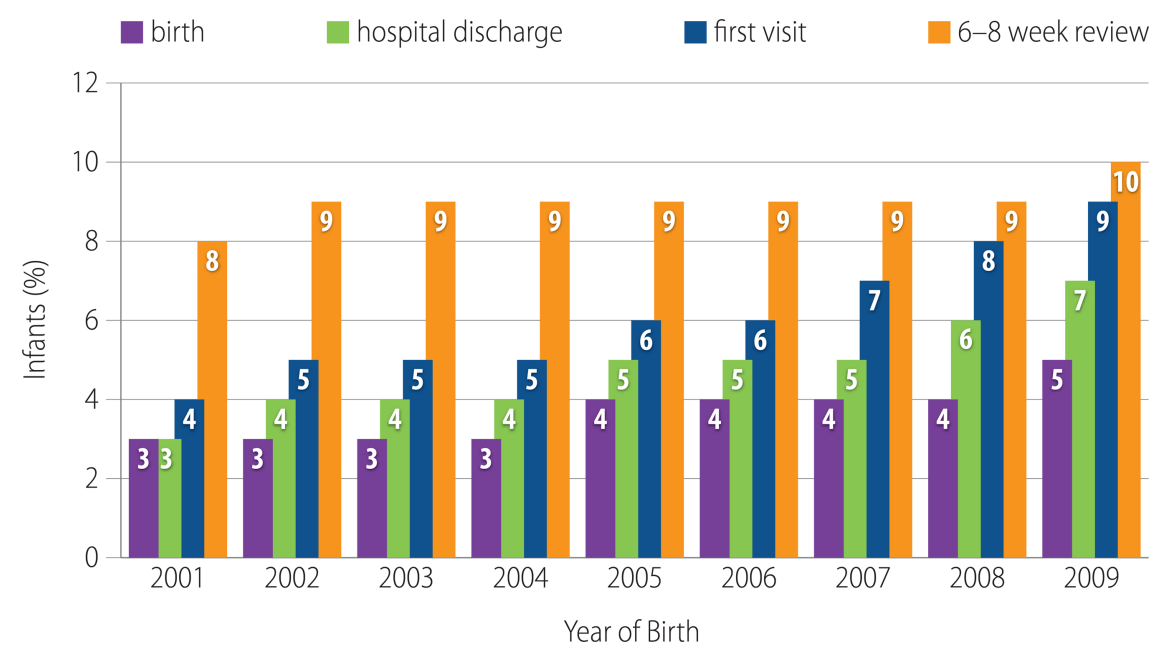


Figure 3 Exclusive breastfeeding trends by mother's country of birth and origin 2001-2009.

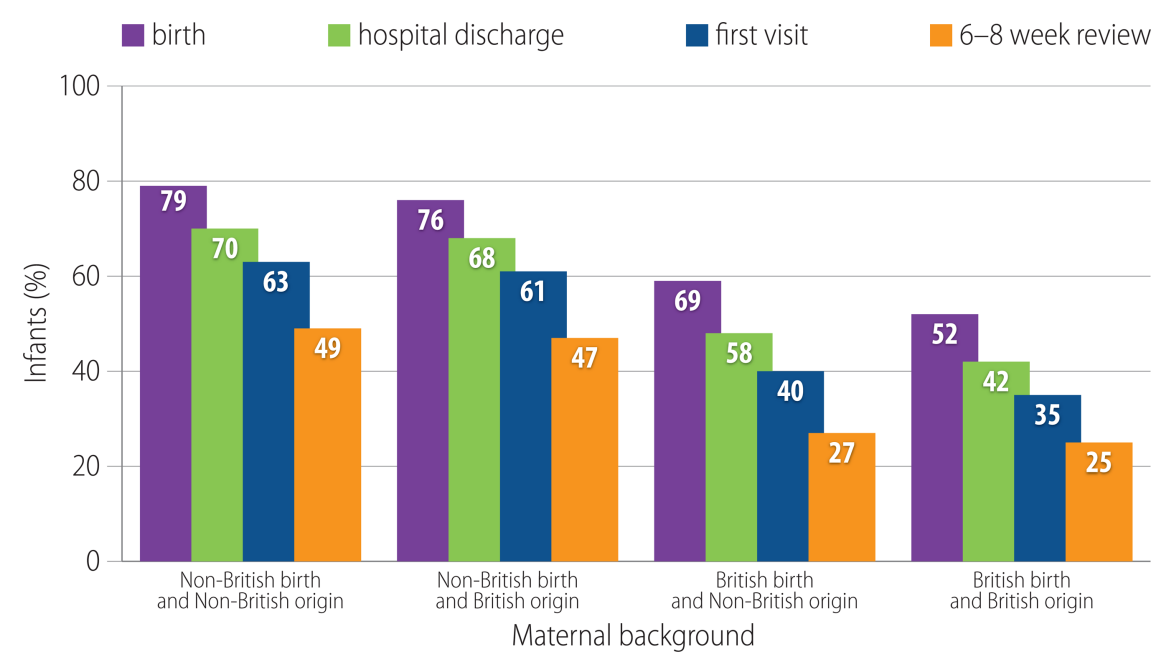

of characteristics at the individual level for a large representative sample of the Scottish infant population.

Record linkage has been described as 'bringing together in one file, records from different sources that relate to the same individual or event'. ${ }^{23}$ ISD Scotland, the organisation that is the main repository for Scottish health services data, has over 30 years experience in developing and implementing linkage methods and has been a key contributor to probabilistic matching techniques developed in Oxford and Canada. ${ }^{20}$ Such data can play a vital role in identifying and targeting scarce resources to vulnerable groups, informing policy, changing clinical practice and supporting local efforts to improve child health. ${ }^{24} 25$

The cohort data over time (1997-2009) enabled monitoring of social and demographic trends. The breadth of information highlights demographic and societal changes-such as increasing ethnic diversity, increasing numbers of older mothers, changes in family structure and rising caesarean rates-that are key determinants of breastfeeding trends. It also provided scope to explore the impact of these determinants on infant feeding in Scotland. For instance, although the crude rates indicated an increase in exclusive breastfeeding trends among infants resident in deprived areas (table 1), this increase was not sustained after adjustment for other social, cultural and demographic factors. ${ }^{26}$

The societal and healthcare associations found with breast feeding in our study are consistent with findings reported in other studies showing a greater chance of breast feeding with increasing age of mother, residence in less deprived areas and less urban settlements among first time mothers, ${ }^{16} 2728$ parents with a non-British birth or origin, ${ }^{29} 30$ female infants, those with a longer postnatal stay in hospital ${ }^{27}$ and among infants born in a baby friendly hospital. ${ }^{16}{ }^{31}$ Conversely, there was less chance of any breast feeding among infants of cohabiting or single/separated parents, ${ }^{28}{ }^{32}$ of a father or mother of a lower socioeconomic status, of mothers who smoked, ${ }^{16} 27$ multiple births, among infants born via instrumental or caesarean section, preterm infants and infants admitted to a neonatal unit. $^{27} 28$ The true strength of these relationships with breast feeding may be underestimated, given that our study tracks feeding up to 6-8 weeks and breast feeding beyond this point cannot be measured from these data, for instance up to 6 months as recommended by current policy. ${ }^{16}$

This study highlights changing patterns of infant feeding in Scotland over the study period. Specifically, the increasing trends in mixed feeding, whereas exclusive breastfeeding rates have remained static. This suggests the need for additional support to mothers in the first few weeks after birth as many mothers who stopped breast feeding before 6 months report that they would have liked to have continued. ${ }^{13}$ In Scotland, $80 \%$ of the births now take place in baby friendly institutions; ${ }^{33}$ an increase in the proportion of skilled staff (and lay persons) trained in managing common lactation problems may help mothers establish the practice of breast feeding after discharge from hospital.

Linkage over time of nationally representative administrative records has advantages over cross-sectional surveys, providing a cost effective way of conducting research with better population coverage and completeness. ${ }^{20} 3435$ Indepth reviews of infant feeding that provide trends across Scotland in large surveys such as the Infant Feeding Survey or the UK Millennium Cohort Study are often limited by the relatively small sample size for Scotland. ${ }^{12}$ Moreover, the unique patient identifier (CHI) used in Scotland enabled efficient pairing of records across different cohort (although some infants who travelled abroad may be 'lost' to follow-up-Personal communication, NHS Central Register Scotland, National Records of Scotland, 2012). Thus, infants who had emigrated could be censored providing potential for prospective time series research or longitudinal analyses.

In addition, it allowed subgroup analysis of those often described as 'hard to reach', for example, ethnic minorities and young mothers in deprived areas, addressing an important requirement of the health services ${ }^{35}$ while also maintaining patient confidentiality of the individuals involved. For example, ethnicity, often poorly recorded on administrative data sources, ${ }^{36}$ was addressed in our study by using derived ethnic/ cultural background. Findings from the derived variables appear to confirm published reports showing higher breastfeeding rates among mothers of non-British background compared with mothers of British background; reflecting possible acculturation among second generation immigrants. ${ }^{29}{ }^{30}$ Furthermore, the (derived) mother's religious background confirmed a tendency to bottle feed observed among certain ethnic minority groups in the UK, for example, mothers of a Muslim background-mainly of Pakistani origin. ${ }^{37}$

In this study, the utility of some of the individual datasets was limited by coverage, discontinuities in recording schemes and revisions to questions or the timing of data collection. Overall, there was still a relatively high coverage and completeness of variables associated with infant feeding at the first visit and the 6-8-week reviews. A slight trend in 'selective' coverage at datasets $^{20}$ and tagging of the migrant status of infants in the 
Table 2 Factors that influence the likelihood of any (exclusive or mixed) breast feeding 1997-2009

\begin{tabular}{|c|c|c|c|c|c|c|}
\hline \multirow[b]{2}{*}{$\begin{array}{l}\text { Background, maternal and infant } \\
\text { health characteristics }\end{array}$} & \multicolumn{3}{|c|}{ First visit review ( 10 days after birth) } & \multicolumn{3}{|l|}{ 6-8-week review } \\
\hline & $\begin{array}{l}\text { Exclusive } \\
\text { breast feeding (\%) }\end{array}$ & $\begin{array}{l}\text { Mixed } \\
\text { feeding (\%) }\end{array}$ & Adjusted OR $(95 \% \mathrm{Cl})$ & $\begin{array}{l}\text { Exclusive } \\
\text { breast feeding (\%) }\end{array}$ & $\begin{array}{l}\text { Mixed } \\
\text { feeding (\%) }\end{array}$ & $\begin{array}{l}\text { Adjusted OR } \\
(95 \% \mathrm{Cl})\end{array}$ \\
\hline \multicolumn{7}{|l|}{ Mother's age } \\
\hline Less than 20 years & 13 & 3 & 1.00 & 6 & 3 & 1.00 \\
\hline $20-24$ years & 23 & 4 & 1.59 (1.54 to 1.64$)$ & 13 & 6 & 1.71 (1.65 to 1.78$)$ \\
\hline $25-39$ years & 37 & 6 & 2.09 (2.02 to 2.16$)$ & 25 & 9 & 2.35 (2.26 to 2.45$)$ \\
\hline $30-34$ years & 48 & 6 & 2.58 (2.49 to 2.66$)$ & 35 & 11 & 3.05 (2.93 to 3.17$)$ \\
\hline $35-39$ years & 50 & 8 & $2.92(2.82$ to 3.02$)$ & 38 & 12 & 3.59 (3.45 to 3.74$)$ \\
\hline 40 years+ & 50 & 9 & 3.33 (3.18 to 3.49 ) & 39 & 13 & 4.21 (4.00 to 4.43$)$ \\
\hline \multicolumn{7}{|l|}{ Marital status } \\
\hline Married & 49 & 7 & 1.00 & 36 & 11 & 1.00 \\
\hline Cohabiting & 30 & 5 & 0.91 (0.90 to 0.93 ) & 19 & 7 & $0.89(0.87$ to 0.90$)$ \\
\hline Single/apart & 16 & 3 & 0.65 (0.64 to 0.67$)$ & 9 & 4 & $0.63(0.61$ to 0.65$)$ \\
\hline \multicolumn{7}{|l|}{ Father's country of birth } \\
\hline British birth & 38 & 5 & 1.00 & 26 & 8 & 1.00 \\
\hline Non-British birth & 59 & 14 & 1.75 (1.69 to 1.80$)$ & 44 & 18 & $1.72(1.66$ to 1.77$)$ \\
\hline Other/unknown & 16 & 3 & 0.67 (0.59 to 0.76$)$ & 9 & 4 & $0.65(0.57$ to 0.74$)$ \\
\hline \multicolumn{7}{|l|}{ Mother's country of birth } \\
\hline Non-British birth & 36 & 5 & 1.00 & 25 & 8 & 1.00 \\
\hline Non-British birth & 62 & 15 & 2.85 (2.77 to 2.94$)$ & 48 & 19 & $2.54(2.47$ to 2.62$)$ \\
\hline \multicolumn{7}{|l|}{ Maternal religious background } \\
\hline Christian & 37 & 5 & 1.00 & 26 & 8 & 1.00 \\
\hline Muslim & 52 & 22 & $0.97(0.90$ to 1.03$)$ & 36 & 25 & $0.90(0.84$ to 0.95$)$ \\
\hline Buddhist & 49 & 18 & 0.44 (0.41 to 0.48$)$ & 40 & 19 & 0.53 (0.49 to 0.58$)$ \\
\hline Hindu & 64 & 17 & $1.22(1.05$ to 1.43$)$ & 49 & 25 & 1.27 (1.11 to 1.46$)$ \\
\hline Sikh & 46 & 13 & 0.56 (0.49 to 0.63 ) & 29 & 19 & 0.64 (0.57 to 0.72$)$ \\
\hline Jewish & 45 & 9 & $1.01(0.78$ to 1.31$)$ & 33 & 13 & $1.09(0.84$ to 1.43$)$ \\
\hline Other/unknown & 49 & 12 & 1.11 (0.99 to 1.26$)$ & 36 & 16 & $1.12(0.98$ to 1.26$)$ \\
\hline \multicolumn{7}{|l|}{ Parents' origin } \\
\hline Both parents of British origin & 38 & 5 & 1.00 & 26 & 8 & 1.00 \\
\hline Mother British and father non-British origin & 53 & 8 & 1.31 (1.25 to 1.37$)$ & 39 & 13 & $1.23(1.17$ to 1.28$)$ \\
\hline Mother non-British and father British origin & 54 & 9 & $1.61(1.54$ to 1.69$)$ & 40 & 13 & $1.59(1.52$ to 1.67$)$ \\
\hline Both parents of non-British origin & 56 & 20 & $1.72(1.61$ to 1.84$)$ & 40 & 23 & $1.50(1.41$ to 1.60$)$ \\
\hline Other/unknown & 22 & 5 & 1.52 (1.35 to 1.71$)$ & 14 & 6 & $1.50(1.34$ to 1.69$)$ \\
\hline \multicolumn{7}{|l|}{ Area deprivation (SIMD 2006) } \\
\hline SIMD 1: Most deprived & 21 & 4 & 1.00 & 13 & 6 & 1.00 \\
\hline SIMD 2 & 31 & 5 & $1.28(1.26$ to 1.30$)$ & 20 & 8 & $1.24(1.21$ to 1.26$)$ \\
\hline SIMD 3 & 41 & 6 & $1.54(1.51$ to 1.57$)$ & 28 & 9 & $1.47(1.44$ to 1.50$)$ \\
\hline SIMD 4 & 51 & 7 & 1.86 (1.82 to 1.89$)$ & 37 & 11 & 1.75 (1.71 to 1.78$)$ \\
\hline SIMD 5: Least deprived & 59 & 7 & 2.14 (2.09 to 2.18$)$ & 44 & 13 & $1.99(1.94$ to 2.03$)$ \\
\hline \multicolumn{7}{|l|}{ Rural/urban residence } \\
\hline Urban & 36 & 6 & 1.00 & 25 & 9 & 1.00 \\
\hline Large town & 41 & 5 & 1.35 (1.30 to 1.41$)$ & 28 & 9 & $1.39(1.33$ to 1.45$)$ \\
\hline Rural & 48 & 6 & 1.39 (1.37 to 1.42$)$ & 35 & 10 & 1.43 (1.41 to 1.46$)$ \\
\hline \multicolumn{7}{|l|}{ Mother's socioeconomic status } \\
\hline Managerial/professional & 60 & 7 & 1.00 & 45 & 13 & 1.00 \\
\hline Intermediate & 39 & 6 & 0.55 (0.54 to 0.56$)$ & 25 & 9 & $0.54(0.53$ to 0.55$)$ \\
\hline Routine/semiroutine occupation & 24 & 4 & $0.43(0.43$ to 0.44$)$ & 15 & 6 & $0.43(0.43$ to 0.44$)$ \\
\hline Students & 34 & 7 & 0.77 (0.73 to 0.81$)$ & 22 & 10 & $0.84(0.79$ to 0.88$)$ \\
\hline Not stated/classified & 27 & 6 & 0.49 (0.48 to 0.51$)$ & 18 & 7 & $0.53(0.51$ to 0.54$)$ \\
\hline \multicolumn{7}{|l|}{ Father's socioeconomic status } \\
\hline Managerial/professional & 58 & 7 & 1.00 & 44 & 12 & 1.00 \\
\hline Intermediate & 45 & 7 & 0.77 (0.76 to 0.79$)$ & 31 & 11 & $0.76(0.75$ to 0.78$)$ \\
\hline Routine/semiroutine occupation & 27 & 5 & $0.55(0.54$ to 0.56$)$ & 17 & 7 & $0.54(0.54$ to 0.55$)$ \\
\hline Students & 48 & 10 & 1.09 (1.03 to 1.17$)$ & 35 & 14 & $1.21(1.13$ to 1.29$)$ \\
\hline Not stated/classified & 18 & 4 & $0.62(0.60$ to 0.65$)$ & 11 & 5 & $0.69(0.66$ to 0.72$)$ \\
\hline \multicolumn{7}{|l|}{ Gender } \\
\hline Male & 38 & 6 & 1.00 & 26 & 9 & 1.00 \\
\hline Female & 38 & 6 & $1.02(1.01$ to 1.03$)$ & 27 & 9 & 1.06 (1.04 to 1.07$)$ \\
\hline \multicolumn{7}{|l|}{ First birth } \\
\hline Multiparous & 38 & 5 & 1.00 & 27 & 8 & 1.00 \\
\hline Primiparous & 39 & 6 & 1.27 (1.25 to 1.29$)$ & 25 & 10 & 1.13 (1.11 to 1.15$)$ \\
\hline
\end{tabular}


Table 2 Continued

\begin{tabular}{|c|c|c|c|c|c|c|}
\hline \multirow[b]{2}{*}{$\begin{array}{l}\text { Background, maternal and infant } \\
\text { health characteristics }\end{array}$} & \multicolumn{3}{|c|}{ First visit review ( 10 days after birth) } & \multicolumn{3}{|l|}{ 6-8-week review } \\
\hline & $\begin{array}{l}\text { Exclusive } \\
\text { breast feeding (\%) }\end{array}$ & $\begin{array}{l}\text { Mixed } \\
\text { feeding (\%) }\end{array}$ & Adjusted OR $(95 \% \mathrm{Cl})$ & $\begin{array}{l}\text { Exclusive } \\
\text { breast feeding (\%) }\end{array}$ & $\begin{array}{l}\text { Mixed } \\
\text { feeding (\%) }\end{array}$ & $\begin{array}{l}\text { Adjusted OR } \\
(95 \% \mathrm{Cl})\end{array}$ \\
\hline \multicolumn{7}{|l|}{ Maternal smoking status at the first visit } \\
\hline Non-smoker & 45 & 6 & 1.00 & 32 & 10 & 1.00 \\
\hline Smoker & 17 & 4 & $0.53(0.52$ to 0.54$)$ & 9 & 5 & $0.46(0.45$ to 0.47$)$ \\
\hline Other/unknown & 39 & 5 & 0.88 (0.86 to 0.91$)$ & 27 & 9 & $0.88(0.86$ to 0.90$)$ \\
\hline \multicolumn{7}{|l|}{ Multiple birth } \\
\hline Singleton & 39 & 5 & 1.00 & 27 & 9 & 1.00 \\
\hline Twins/triplets & 21 & 15 & 0.55 (0.53 to 0.57$)$ & 11 & 14 & 0.50 (0.48 to 0.52$)$ \\
\hline \multicolumn{7}{|l|}{ Mode of delivery } \\
\hline Normal/spontaneous & 39 & 5 & 1.00 & 27 & 8 & 1.00 \\
\hline Instrumental & 41 & 6 & 0.81 (0.79 to 0.83 ) & 28 & 10 & $0.82(0.81$ to 0.84$)$ \\
\hline Breech delivery & 29 & 9 & 0.96 (0.87 to 1.06$)$ & 17 & 10 & $0.89(0.79$ to 0.99$)$ \\
\hline Caesarean—emergency & 35 & 7 & $0.61(0.60$ to 0.63$)$ & 24 & 10 & $0.62(0.60$ to 0.64$)$ \\
\hline Caesarean-elective & 36 & 8 & 0.68 (0.66 to 0.69$)$ & 24 & 10 & 0.70 (0.69 to 0.72$)$ \\
\hline Other unknown & 40 & 7 & 0.61 (0.50 to 0.74 ) & 29 & 9 & $0.57(0.46$ to 0.71$)$ \\
\hline \multicolumn{7}{|l|}{ Neonatal admission } \\
\hline Not admitted & 39 & 5 & 1.00 & 27 & 9 & 1.00 \\
\hline Admitted $\leq 48 \mathrm{~h}$ & 32 & 6 & 0.80 (0.77 to 0.82 ) & 21 & 8 & 0.83 (0.80 to 0.86$)$ \\
\hline Admitted $>48 \mathrm{~h}$ & 29 & 9 & $0.88(0.85$ to 0.90$)$ & 17 & 10 & $0.83(0.80$ to 0.86$)$ \\
\hline Other unknown & 40 & 6 & 1.09 (1.05 to 1.13$)$ & 28 & 10 & 1.10 (1.07 to 1.14$)$ \\
\hline \multicolumn{7}{|l|}{ Estimated gestation } \\
\hline Normal (37-42 weeks) & 39 & 5 & 1.00 & 27 & 9 & 1.00 \\
\hline Preterm (<37 weeks) & 28 & 9 & $0.93(0.91$ to 0.96$)$ & 15 & 10 & $0.82(0.79$ to 0.84$)$ \\
\hline Post-term (>42 weeks) & 43 & 6 & $1.14(1.10$ to 1.19$)$ & 32 & 9 & $1.20(1.15$ to 1.24$)$ \\
\hline Other unknown & 40 & 7 & 0.66 (0.53 to 0.81$)$ & 29 & 9 & $0.65(0.52$ to 0.82$)$ \\
\hline \multicolumn{7}{|l|}{ Postnatal stay in hospital } \\
\hline 2 days or shorter & 37 & 5 & 1.00 & 26 & 8 & 1.00 \\
\hline $3-5$ days & 40 & 6 & $1.23(1.21$ to 1.25$)$ & 27 & 10 & 1.15 (1.13 to 1.17$)$ \\
\hline $6-20$ days & 39 & 11 & $1.64(1.59$ to 1.69$)$ & 24 & 13 & 1.39 (1.35 to 1.44$)$ \\
\hline Other/unknown & 41 & 7 & 2.57 (2.27 to 2.91$)$ & 30 & 9 & 2.63 (2.32 to 2.99 ) \\
\hline \multicolumn{7}{|l|}{ Baby Friendly Initiative (Hospital) } \\
\hline Not accredited & 41 & 7 & 1.00 & 25 & 8 & 1.00 \\
\hline Baby friendly & 36 & 5 & $1.14(1.13$ to 1.16$)$ & 28 & 9 & $1.14(1.13$ to 1.16$)$ \\
\hline $\begin{array}{l}\text { Age at review } \\
\text { Age at review }\end{array}$ & 38 & 6 & Not significant & 27 & 9 & $0.99(0.99$ to 0.99$)$ \\
\hline \multicolumn{7}{|l|}{ Year of birth } \\
\hline 1997-2009 & 38 & 6 & $1.00(0.99$ to 1.00$)$ & 27 & 9 & $0.99(0.99$ to 0.99$)$ \\
\hline
\end{tabular}

subsequent child health review visits has been reported by others. $^{38}$ The relatively short duration of infant feeding captured on the child health surveillance schemes may restrict the potential of exploiting the linked records in research; data schemes that provided more information on the duration of infant feeding have been discontinued. Moreover, the definition of infant feeding as the predominant mode of feeding the day before data collection (dependent on the interpretation of health worker who collects the information) was not consistent with the definition used in the Infant Feeding Survey or recommended by WHO and may bias the results.

The current findings build a 'population profile' comprising a range of factors that independently influence the chances of establishing infant feeding in Scotland. The need for an 'enabling environment' to increase initiation and duration of breast feeding in Scotland is emphasised. This environment will be influenced by cultural background otherwise described as 'embodied knowledge', 39 family and other social circumstances and health service factors-such as the mode of delivery and implementation of baby friendly practices.

\section{CONCLUSIONS}

Breast feeding is an effective intervention for reducing the risk of childhood diseases and addressing health inequalities through to adulthood. ${ }^{15}$ Several recommendations have been made to improve breastfeeding rates; however, there is little evidence of changing trends in Scotland overall, although trends in some local areas have changed significantly, due to demographic, cultural and socioeconomic impacts. 6240

In Scotland, the predominantly bottle feeding culture is yet to give way to a breastfeeding culture, although some may argue that rising rates of mixed feeding may be the transition between both extremes. Nevertheless, it highlights the need for a more supportive environment and multifaceted interventions across the population in order to improve breastfeeding trends in Scotland. 
This project has demonstrated an effective framework for using linked data collated from surveillance and administrative records in child health research. This approach provides clear benefits for the Scottish population, without imposing additional risk or burdens to individuals within it. It provides a resource for understanding Scotland's changing demography and potential for subgroup analysis, which could be used to better inform policies and programmes. Moreover, the results, which are consistent with other findings, provide a 'Scottish context' that could be further exploited to improve child health outcomes and facilitate a broader, 'joined-up' perspective for addressing feeding in the early years.

There is strong argument for using linked datasets to provide indepth analysis of child health trends in Scotland prospectively in order to guide both qualitative and quantitative research, inform policy, design health promotion initiatives and monitor population health.

\section{What is already known on this subject}

Although breast feeding is regarded as an important public health intervention for safeguarding child health, there has been little change in the breast feeding trends in Scotland.

\section{What the study adds}

This study has confirmed the strength of association between a range of cultural, family, health service, infant and maternal health characteristics and the likelihood to breast feed in a Scottish context.

\section{Policy implications}

- A wide range of factors influence the likelihood to establish or sustain breast feeding in Scotland.

- Interventions to increase breastfeeding rates in Scotland should extend beyond the health service, engage the entire population and consider the wider context of changing demographic and cultural influences.

- The potential of administrative datasets to provide vital intelligence on population health and 'hard to reach' subgroups can be improved and exploited further in order to inform, influence and monitor child health policy.

Acknowledgements The authors are grateful to Pauline Craig who was involved in the initial stages of the study design/project set up and to James Boyd for his contribution to early drafts of the manuscript. We also gratefully acknowledge funding provided by the Scottish Collaboration of Public Health Research and Policy (SCPHRP) and the Glasgow Centre for Population Health (GPCH).

Collaborators GCPH Steering Group Members: Bruce Whyte (GCPH), Pauline Craig (NHS Health Scotland, formerly GCPH), Jim Chalmers (ISD Scotland), Linda Wolfson (Infant Feeding Advisor, NHS GG\&C), Rachel Wood (ISD Scotland), David Tappin (Paediatric Epidemiology and Child Health Unit, Royal Hospital for Sick Children, Glasgow), Ali McDonald (NHS Health Scotland), Judith Tait (Child Health Information Team, ISD Scotland), Jill Muirie (NHS Health Scotland), Kate Woodman (NHS Health Scotland), Ruth Campbell (Consultant Dietician, NHS Ayrshire \& Arran), Helen Yewdall (Scottish Government), James Egan (GCPH) and Omotomilola Ajetunmobi (ISD, Scotland).
Contributors OA cleaned, analysed and interpreted the data and prepared the first draft/revisions of the final manuscript; BW designed and managed the study, and also interpreted the results, drafted and revised the manuscript; JC was involved in the study design and reviewed drafts of the manuscript; MF linked the datasets and reviewed drafts of the manuscript; DS provided guidance in the analysis and interpretation of the data; RW was involved in data interpretation and review of the draft manuscript. All authors approved the final draft. DS and BW are the guarantors. All members of the GCPH Breastfeeding Steering Group provided guidance in the implementation of the project and interpretation of the data.

Funding The project was jointly funded by the Scottish Collaboration of Public Health Research and Policy (SCPHRP-SCPH/08) and the Glasgow Centre for Population Health. The SCPHRP had no role in the study design, collation, analysis, interpretation and decision to publish.

Competing interests None.

Ethics approval Privacy Advisory Committee (PAC), NHS National Services Scotland.

Provenance and peer review Not commissioned; externally peer reviewed.

Data sharing statement The routine data analysed for this study are held by NHS National Services Scotland, Information Services Division.

Open Access This is an Open Access article distributed in accordance with the Creative Commons Attribution Non Commercial (CC BY-NC 3.0) license, which permits others to distribute, remix, adapt, build upon this work non-commercially, and license their derivative works on different terms, provided the original work is properly cited and the use is non-commercial. See: http://creativecommons.org/ licenses/by-nc/3.0/

\section{REFERENCES}

1 Brookes EL, Rosman DL, Holman CDJ, et al. Public good through data linkage: measuring research output from the Western Australian data linkage system. Aust $N$ Z J Public Health 2008;32:19-23.

2 Scottish Government. Scotland-wide Data Linkage Framework. (web publication) http://www.scotland.gov.uk/Topics/Statistics/datalinkageframework (accessed Dec 2012).

3 Forsyth JS. Policy and pragmatism in breastfeeding. Arch Dis Child 2011;96:909-10.

4 Yngve A, Sjörström M. Breastfeeding framework and suggested framework for action in Europe. Public Health Nutr 2001:4:729-39.

5 Scottish Government. The Early Years Framework. 2009 (web publication) http:/l www.scotland.gov.uk/publications/2009/01/13095148/5 (accessed Dec 2012).

6 Scottish Government. Improving Maternal and Infant Nutrition: A Framework for Action. 2011 http://scotland.gov.uk/Publications/2011/01/13095228/0 (accessed Dec 2012).

7 Callen J, Pinelli J. Incidence and duration of breastfeeding for term infants in Canada, United States, Europe and Australia: a literature review. Birth 2004:31:285-91.

8 ScotPHO website. http://www.scotpho.org.uk/comparative-health/scotland-andeuropean-hfa-database (accessed Dec 2012: provides comparative information for Scotland/Europe for breastfeeding rates at 3 months and 6 months until 2004).

9 Ferguson AE, Tappin DM, Girdwood RWA, et al. Breastfeeding in Scotland. Br Med J 1994:308:824-25

10 ISD Scotland. Child Health —Infant feeding website. http://www.isdscotland.org/ Health-Topics/Child-Health/Infant-Feeding (accessed Sep 2012).

11 Tappin DM, Mackenzie JM, Brown AJ, et al. Comparison of breastfeeding rates in Scotland 1990-1 and 1997-8. Br Med J 2001;322:1335-6.

12 Scottish Government. Millennium cohort study: exploration of some distinctive results for Scotland (edited by Shirley Dex, Centre for Longitudinal Studies, Institute of Education, University of London) http://www.scotland.gov.uk/Publications/2007/ 12/18133613/0 (accessed Nov 2012).

13 McAndrew F, Thomson J, Fellow L, et al. Infant feeding survey 2010. Health and Social care Information Centre 2012: IFS 2010 results on the trends chapter 2. https://catalogue.ic.nhs.uk/publications/public-health/surveys/infant-feed-surv2010/ifs-uk-2010-chap2-inc-prev-dur.pdf (accessed Jul 2013).

14 Bradshaw P, Martin C, Cunningham S. Growing up in Scotland: Exploring the experience and outcomes for advantaged and disadvantaged families. 2008. http:/l www.scotland.gov.uk/Publications/2008/03/12101843/5 (accessed Aug 2009).

15 Gökçay G. Breastfeeding for the sake of Europe and the world. Child Care Health Dev 2009:35:293-7.

16 Hoddinott P, Tappin D, Wright C. Breastfeeding (Clinical Review). Br Med J 2008;336:881-7.

17 Flanagan L, Gordon D. What is known about maternal and infant feeding in Scotland? NHS Health Scotland and Scottish Public Health Observatory Publication 2010 (web publication) http://www.scotpho.org.uk/publications/reports-and-papers/ 480-what-is-known-about-maternal-and-infant-nutrition-in-scotland-(accessed Jan 2011). 
18 National Privacy Advisory Committee. http://www.nhsnss.org/pages/corporate/ privacy_advisory_committee.php (accessed Aug 2012).

19 Kendrick SW, Douglas MM, Gardner D, et al. Best link matching of Scottish health data sets. Methods Inf Med 1998;37:64-8.

20 Fleming M, Kirby B, Penny KI. Record linkage in Scotland and its application to health research. J Clin Nurs 2012;21:2711-21.

21 Mateos $\mathrm{P}$, Longley $\mathrm{P}$, Webber R. The cultural, ethnic and linguistic classification of populations and neighbourhoods using personal names. University College London, Centre for Advanced Spatial Analysis. CASA working paper 2007:116. http://www. bartlett.ucl.ac.uk/casa/publications/working-paper-116 (accessed Aug 2012).

22 Lakha F, Gorman DR, Mateos P. Name analysis to classify populations by ethnicity in public health: validation of Onomap in Scotland. Public Health 2011;125:688-96.

23 Hobbs MST, McCall MG. Health statistics and record linkage in Australia. J Chronic Dis 1970;23:375-81.

24 Buehler JW, Prager K, Hogue CJR. The role of linked birth and infant death certificates in maternal and child health epidemiology in the United States. Am J Prev Med 2000;19(1S):3-11.

25 Hertzman C. The role of administrative record linkage in creating trajectories of early human development. Healthc Policy 2011;6:55-62.

26 Ajetunmobi O, Whyte B. Deprivation and infant feeding at birth. Arch Dis Child 2012;97:A183-6 (abstract).

27 Dennis C. Breastfeeding initiation and duration: a 1990-2000 literature review. J Obstet Gyneacol Neonatal Nurs 2002:31:12-32.

28 Thullier D, Mercer J. Variables associated with breastfeeding duration. J Gynaecol Neonatal Nurs 2009:38:259-68.

29 Griffiths LJ, Tate AR, Dezateux C, et al. The contribution of parental and community ethnicity to breastfeeding practices: evidence from the millennium cohort study. Int J Epidemiol 2005;34:1378-86.
30 Griffiths LJ, Tate AR, Dezateux C, et al. Do early infant feeding practices vary by maternal ethnic group? Public Health Nutr 2007;10:957-64.

31 Broadfoot M, Britten J, Tappin DM. The baby friendly hospital initiative and breastfeeding rates in Scotland. Arch Dis Child Fetal Neonatal Educ2005;90: F114-118.

32 Kiernan K, Picket KE. Marital status disparities in maternal smoking during pregnancy, breastfeeding and maternal depression. Soc Sci Med 2006;63:335-46.

33 UNICEF Baby Friendly UK. http://progress.babyfriendly.org.uk/htables/all_hospitals acc_status.asp (accessed Jul 2013).

34 The West of Scotland Coronary Prevention Study Group. Computerised record linkage compared with traditional follow up methods in clinical trials illustrated in a prospective cohort epidemiological study. J Clin Epidemiol 48:1441-52.

35 Boyd KM. Ethnicity and the ethics of data linkage. BMC Public Health 2007;7:318-20.

36 Johanan C, Blakely T, Bansal N, et al. Linkage of data in the study of ethnic inequalities and inequities in health outcomes in Scotland, New Zealand and the Netherlands: Insights on the global study of ethnicity and health. Public Health 2012;126:245-7

37 Sarwar T. Infant feeding practices of Pakistani mothers in England and Pakistan. J Hum Nutr Diet 2002;15:419-28.

38 Wood R, Stirling A, Nolan C, et al. Trends in coverage of 'universal' child health reviews: observational study using routinely available data. BMJ Open 2012;2: e000759.

39 Hoddinott P, Pill R. Qualitative study of decisions about infant feeding among women in east end of London. Br Med J 1999:318:30-4.

40 Glasgow Centre for Population Health. Community Health \& Wellbeing Profiles for Greater Glasgow and Clyde. 2008. http://www.gcph.co.uk/communityprofiles (accessed Dec 2012) 